\title{
Factors affecting severe weather threat index in urban areas of Turkey and Iran
}

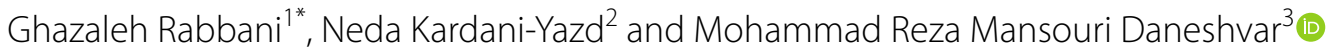

\begin{abstract}
Background: Distinguishing dynamic variations of the climate from the physical urban indicators is a challenge to assess the factors affecting weather severity. Hence, the time-series of the severe weather threat index (SWEAT) were considered in the four urban areas of Turkey and Iran to identify its affecting factors among the climatic variables and urban indicators in 2018. The SWEAT data were obtained from the upper-air sounding database of the University of Wyoming. The climatic variables were extracted from the Asia Pacific data research center (APDRC). The spatial statistics for urban expansion were collected from global human built-up and settlement extent (HBASE) data sets. A quantitative measuring of the Pearson correlation test was used to expose the relationships between dependent index (SWEAT) and independent variables (climatic and anthropogenic).

Results: Results revealed that the high and extreme severity classes of the weather condition in the Ankara, Istanbul, Mashhad, and Tehran are estimated as 7.7\% (28 days), 15.3\% (56 days), 1.1\% (4 days), and 4.4\% (16 days), respectively. The strongest values of the annual SWEAT index, exposing the unstable and severe weather conditions, were observed for Istanbul and Ankara urban regions. This result may be corresponding to the highest values of mean annual precipitation and relative humidity in addition to the largest values of urban expansion and sprawl index. The statistical correlation tests in annual scale confirmed the effective role of climatic elements of precipitation, relative humidity, and cloudiness (R from 0.94 to 0.99 ) and the urban expansion indicators (R from 0.86 to 0.91 ) in increasing annual severe weather index of SWEAT at above $85-95 \%$ of confidence level.

Conclusions: The correlations between the urban expansion indicators and outcome SWEAT index can be strengthened by some climatic elements (e.g., precipitation, humidity, and cloudiness), revealing the mediator and magnifier task. However, the mentioned correlations can be weakened by another climatic variable (i.e., air temperature), revealing a moderator and modifier task. Ultimately, investigation of the weather severity indices (e.g., SWEAT index) could be applied to identify the local and regional evidence of climate change in the urban areas.
\end{abstract}

Keywords: Climatic variables, Correlation test, Mediation indicator, Urban expansion

\section{Background}

Urban growth is an issue that intensely affects local climate and its notable changes in recent decades (Bazrkar et al. 2015). Urban activities such as the high volume of traffics and constructional functions have an important role in urban thermal effects and air dynamics (Fan

\footnotetext{
*Correspondence: ghazaleh.rabbani@gmail.com

${ }^{1}$ College of Geography and Urban Planning, Research Institute

of Shakhes Pajouh, Isfahan, Iran

Full list of author information is available at the end of the article
}

and Sailor 2005; Makar et al. 2006) with intensifying the emissions of greenhouse gases (Dodman 2009). A great share of greenhouse gas emissions and subsequent effects such as the alterations of air temperature, precipitation, and humidity depends on the urbanization in the Middle East region, which is suffered by the climate change effects such as dust emissions and storms (Gohari et al. 2013; Shepherd et al. 2016; Mansouri Daneshvar et al. 2019a).

Literature revealed that the increase in urban population, as well as urbanization, could enhance the 
transportation and heat effect (Dulal et al. 2011). In vice versa, the urban heat effect can play the main role in the increase of the surface temperature (Alpert et al. 2005). Fanni et al. (2013) and Elasha (2010) have indicated that the severe effects of climatic change accompanied by urban growth in Iran and the Middle Eastern region. In a recent paper, Mansouri Daneshvar et al. (2019b) confirmed the possible effects of urbanization on the climatic variations through a positive correlation between four climatic parameters (surface temperature, surface longwave flux, total ozone, and black carbon density) and urban sprawl (R from 0.83 to 0.98). Meanwhile, Sarvari (2019) revealed a parallel increase for temperature and upward long-wave radiation adjusted by the increasing urban population through significant and strong relationships ( $\mathrm{R}$ from 0.81 to 0.99). Despite these researches, sufficient attempts were not observed to reveal the urban effects on the severe weather indices (e.g., thunderstorm or air perturbation). Hence, the research problem of this study depends on the identification of some assumed factors affecting the local climate perturbation in the urban regions. This gap, as the main challenge, drives the research context through the assumption of severe weather index and presentation of a quantitative and comparative approach to solving this problem by using the relevant international databases and statistical correlative methods. On this basis, this paper will provide two main contributions including: (1) a theoretical background regarding the weather severity and perturbation in the urban regions, and (2) finding the facts and statistics to detect the factors affecting weather severity and its possible correlations with other local climatic and anthropogenic variables.

Based on the quantities of the urban air levels, severe weather threat index (SWEAT), as a significant weather predictor (Wang et al. 2014), reflects the air perturbation and severe weather through day-by-day monitoring using the radiosonde stations. Kaltenböck et al. (2009) have noted that substantial indices derived from radiosonde data, e.g., Lifted index (Galway 1956), Showalter index (Showalter 1953), and SWEAT index (Bidner 1970; Miller 1972), are often used to discriminate between ordinary and severe convection of air masses, incorporating thermodynamic as well as kinetic formation mechanism over each region (Sioutas and Flocas 2003). Among these indices, the SWEAT index is a good indicator for measuring atmospheric instability and the likelihood of storms (Siedlecki 2009).

The SWEAT index combines measures of moisture, lapse rate, and vertical shear in a very simple way to determine the likeliness of the convective environment and severe weather (Wasula et al. 2002). SWEAT index, in addition to forecasting the convective potentials of the weather and the thunderstorms (Miller and Mote 2018), can be used to represent the atmospheric indications in the urban areas (Baltaci et al. 2018). The application of the SWEAT index is broadly observed to detect the convective parameters of thunderstorm activity in several regions such as Greece (Sioutas and Flocas 2003), United States (Derubertis 2006), Ireland (Tyrrell 2007), Germany (Kunz 2007), Cyprus (Michaelides et al. 2008), Gulf of Mexico (Rhodes and Senkbeil 2014), and North Caucasus (Abshaev et al. 2019). These researches dominantly have examined the index in the non-urban areas. Hence, a new examination seems to be needed to investigate the index in the urban regions.

Although, Derubertis (2006) have noted several factors influencing weather severity and storm records including population density, urbanization, and highway distribution, the distinguishing dynamic variation of the climate from these physical artifacts are the challenge. Hence, the present study aims to investigate the diurnal changes of SWEAT index in the four urban areas of Turkey and Iran in addition to recognizing affecting factors such as climatic variables (air temperature, precipitation, relative humidity, and cloudiness) and urban indicators (urban expansion and population growth). Assessment of the SWEAT index to determine the urban effects in severe weathering and storming is the main originality of the present research.

\section{Materials and methods Study area}

The study site is located in selected urban areas of Turkey and Iran countries named Istanbul, Ankara, Tehran, and Mashhad along the $\sim 35^{\circ}-40^{\circ}$ Northern latitudes of the Middle East region (Fig. 1). The reason for selecting these urban areas relates to choosing the largest cities of Turkey and Iran with a minimum threshold of the population above 3,000,000 inhabitants and their similar geographical latitude, which is the middle part of AlpHimalayan elevation belt in the northern hemisphere's mid-latitudes. Each study region was assumed in a rectangle zone exactly around the city cores with the same area $\sim 3500 \mathrm{Km}^{2}$ and geographical coordination of $30^{\prime}$ $\mathrm{N} \times 40^{\prime} \mathrm{E}$ arcs, comprised of urban and pre-urban expansions in 2018 (Fig. 2).

Ankara (Fig. 2a) with 4.9 million inhabitants (WUP 2018) is laid between northern latitudes from $39^{\circ} 40^{\prime}$ to $40^{\circ} 10^{\prime}$ and eastern longitudes from $32^{\circ} 30^{\prime}$ to $33^{\circ} 10^{\prime}$ with mean elevation value of about $890 \mathrm{~m}$ above sea level. Istanbul (Fig. 2b) with 14.7 million inhabitants (WUP 2018) is laid between northern latitudes from $40^{\circ} 50^{\prime}$ to $41^{\circ} 20^{\prime}$ and eastern longitudes from $28^{\circ} 40^{\prime}$ to $29^{\circ} 20^{\prime}$ with mean elevation value of about $20 \mathrm{~m}$ above sea level. Mashhad (Fig. 2c) with 3.0 million inhabitants (WUP 


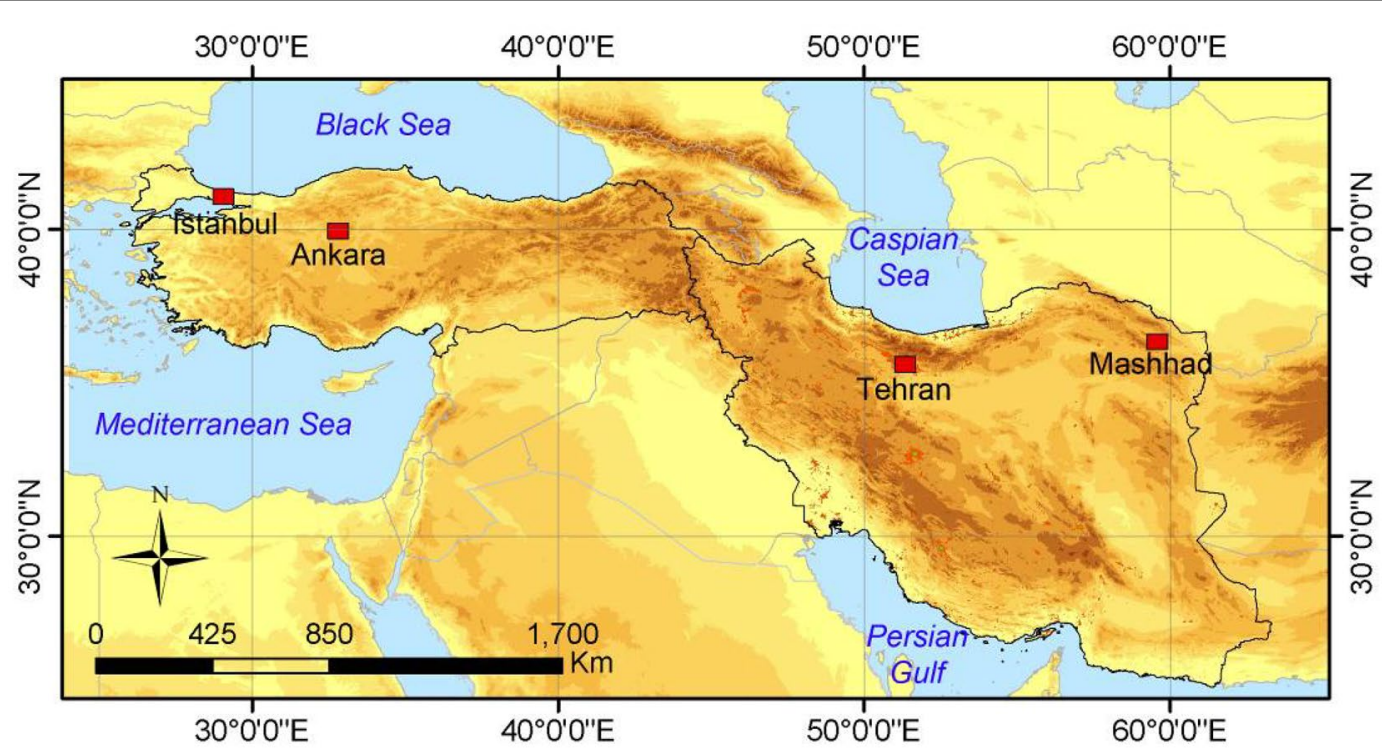

Fig. 1 Geographical location of the study areas

2018) is laid between northern latitudes from $36^{\circ} 05^{\prime}$ to $36^{\circ} 35^{\prime}$ and eastern longitudes from $59^{\circ} 15^{\prime}$ to $59^{\circ} 55^{\prime}$ with mean elevation value of about $1,190 \mathrm{~m}$ above sea level. Besides, Tehran (Fig. 2d) with 8.9 million inhabitants (WUP 2018) is laid between northern latitudes from $35^{\circ} 20^{\prime}$ to $35^{\circ} 50^{\prime}$ and eastern longitudes from $51^{\circ} 00^{\prime}$ to $51^{\circ} 40^{\prime}$ with mean elevation value of about $990 \mathrm{~m}$ above sea level. The spatial alteration of based on the digital elevation model (DEM) for the study regions indicated the mean elevation values from $20 \mathrm{~m}$ above sea level to 1,190 $\mathrm{m}$ above sea level (Table 1).

According to the climate classification of Köppen-Geiger, proposed by Beck et al. (2018) and Peel et al. (2007), Istanbul and Ankara are located in the warm temperate zone and Tehran and Mashhad are located in the warm arid zone. The total annual precipitation and mean annual temperature of the study areas were recorded as $150-950 \mathrm{~mm}$ and $14-21^{\circ} \mathrm{C}$, respectively, derived from a global database of WorldClim in a long-term period of 1950-2000 (Hijmans et al. 2005). The amount of annual average precipitation in the study regions represented a decrease from the western to the eastern longitudes (from Istanbul to Mashhad) by about $800 \mathrm{~mm}$. As well, the amount of annual average temperature increases by about $7{ }^{\circ} \mathrm{C}$.

\section{Data preparation}

The SWEAT index evaluates the potential for the severe weather conditions in each region by combining low-level $(850-\mathrm{hPa})$ moisture, thermal instability (as expressed by the total totals index) and warm air advection (as expressed by the wind shear between levels 850 and $500-\mathrm{hPa}$ ). The SWEAT index (unit-less) is articulated according to the original work of Miller (1972) and the next developments by Sioutas and Flocas (2003); Bauman et al. (2005); Wang et al. (2014) and Das (2017) through the following equation (Eq. 1):

$$
\begin{aligned}
\text { SWEAT }= & 12 \mathrm{~T}_{\mathrm{d} 850}+20(\mathrm{TT}-49)+2 \mathrm{f}_{850} \\
& +\mathrm{f}_{500}+125(\mathrm{~S}+0.2)
\end{aligned}
$$

Where, $\mathrm{T}_{\mathrm{d} 850}$ is the dew point $\left({ }^{\circ} \mathrm{C}\right)$ at $850 \mathrm{hPa} . \mathrm{f}_{850}$ and $\mathrm{f}_{500}$ are the wind velocity (knots) at $850 \mathrm{hPa}$ and $500 \mathrm{hPa}$, respectively. TT is the total totals index equal to $\mathrm{T}_{850}+\mathrm{T}_{\mathrm{d} 850-} 2 \mathrm{~T}_{500}$, where $\mathrm{T}_{850}$ and $\mathrm{T}_{500}$ are the air temperature $\left({ }^{\circ} \mathrm{C}\right)$ at $850 \mathrm{hPa}$ and $500 \mathrm{hPa}$, respectively. $\mathrm{S}$ is the wind shear equal to $\sin \left(\mathrm{d}_{500}-\mathrm{d}_{850}\right)$, where $\mathrm{d}_{850}$ and $\mathrm{d}_{500}$ represent the wind direction (in $0^{\circ}-360^{\circ}$ ) at $850 \mathrm{hPa}$ and $500 \mathrm{hPa}$, respectively (Sioutas and Flocas 2003; Kunz 2007; Wang et al. 2014). If any term of the equation is negative, it is set to zero. The values of more than 300 indicate a strong potential for severe thunderstorms, while values over 400 indicate tornado activity (Derubertis 2006). According to Bauman et al. (2005), the classification of the weather severity is defined as low, high, and extreme classes for SWEAT values $<200,200-300$, and $>300$, respectively. The SWEAT value above 300 could be related to the lower threshold for the occurrence of the extreme thunderstorms (Peppier 1988), but the average SWEAT index associated warm season storms usually fell above 200 (Derubertis 2006). 


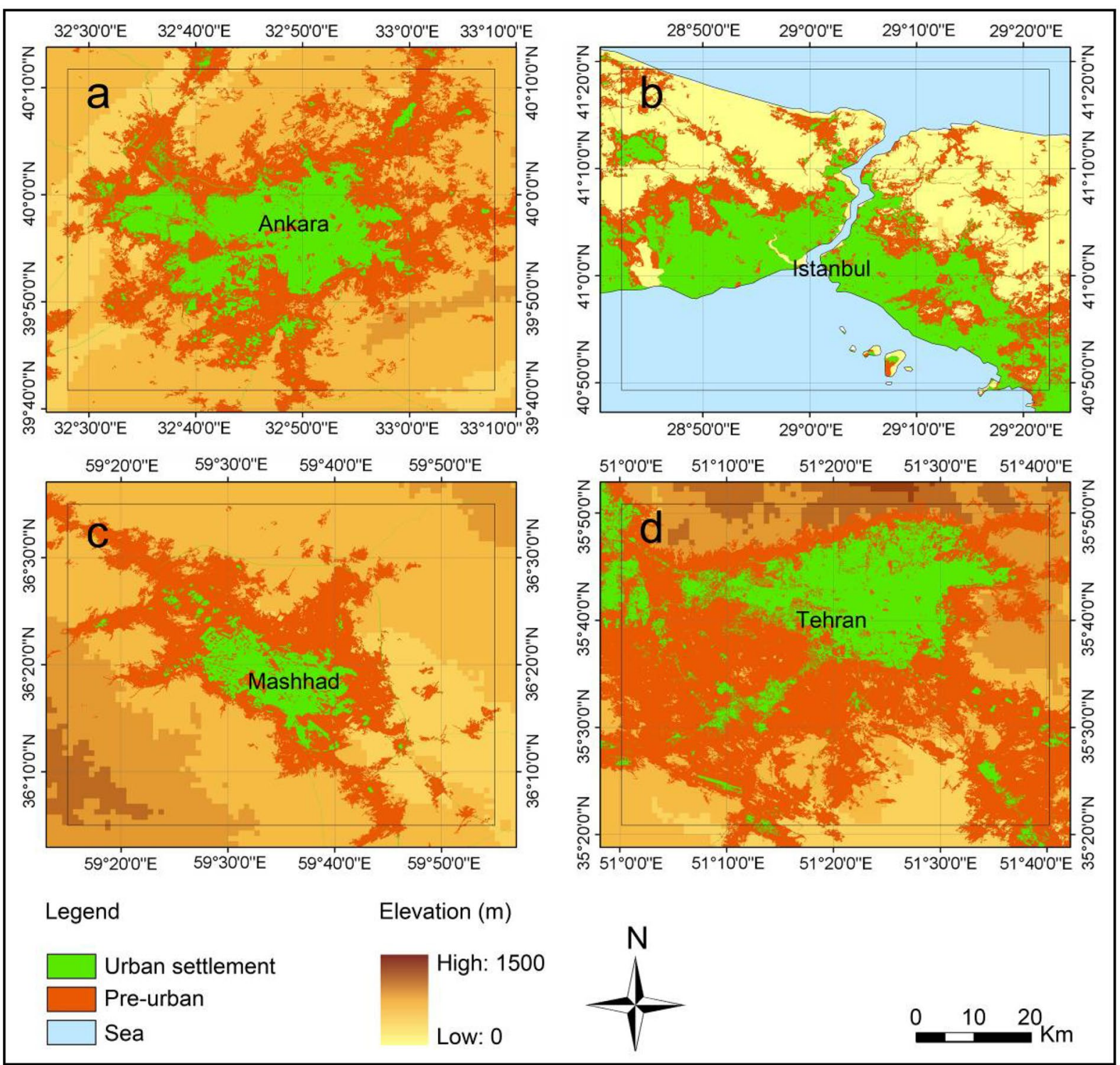

Fig. 2 Rectangle zone of each study area comprised of urban and pre-urban expansions in 2018 for a Ankara, b Istanbul, c Mashhad, and d Tehran

Table 1 Spatial and demographic profile of four case studies in 2018

\begin{tabular}{llllcc}
\hline No. & City & Latitude $\left(^{\circ}\right)$ & $\begin{array}{l}\text { Longitude } \\
\left({ }^{\circ}\right)\end{array}$ & Altitude $(\mathbf{m})$ & $\begin{array}{l}\text { Population } \\
\text { (million) }\end{array}$ \\
\hline 1 & Ankara & 39.920 & 32.854 & 890 & 4.9 \\
2 & Istanbul & 41.014 & 28.950 & 20 & 14.7 \\
3 & Mashhad & 36.297 & 59.606 & 990 & 3.0 \\
4 & Tehran & 35.694 & 51.422 & 1190 & 8.9 \\
\hline
\end{tabular}

In this research, the sounding and air vertical data were obtained directly to extract daily SWEAT data from the University of Wyoming upper-air sounding database via http://weather.uwyo.edu/upperair/sounding.html during 365 days of 2018 for Ankara (code: 17130), Istanbul (code: 17064), Mashhad (code: 40745), and Tehran (code: 40754) radiosonde stations. Owing to the limitation in the daily-scale big-data compilation of the SWEAT index from radiosonde stations, the temporal window of this research focuses on 365 days in 2018.

Owing to data accessibility of time series, the climatic variables of air temperature, precipitation, relative humidity, and cloudiness were extracted from the Asia Pacific Data Research Center (APDRC) data set, hosted by the National Oceanic and Atmospheric Administration (NOAA), via http://apdrc.soest.hawaii.edu/las/getUI 
.do for the spatial location of the study areas. All aforementioned variables, by diurnal scale, were extracted for each urban area and then were processed and formatted by monthly and annual scales. For instance, areaaveraged daily time-series of the climatic variable of relative humidity and temperature in 2018 conspired as an adjusted rescaled plot for all case studies Fig. 3.

As well, the daily NOAA/NCEP reanalysis was used to composite anomalous data grids including the atmospheric variations of air temperature and geopotential

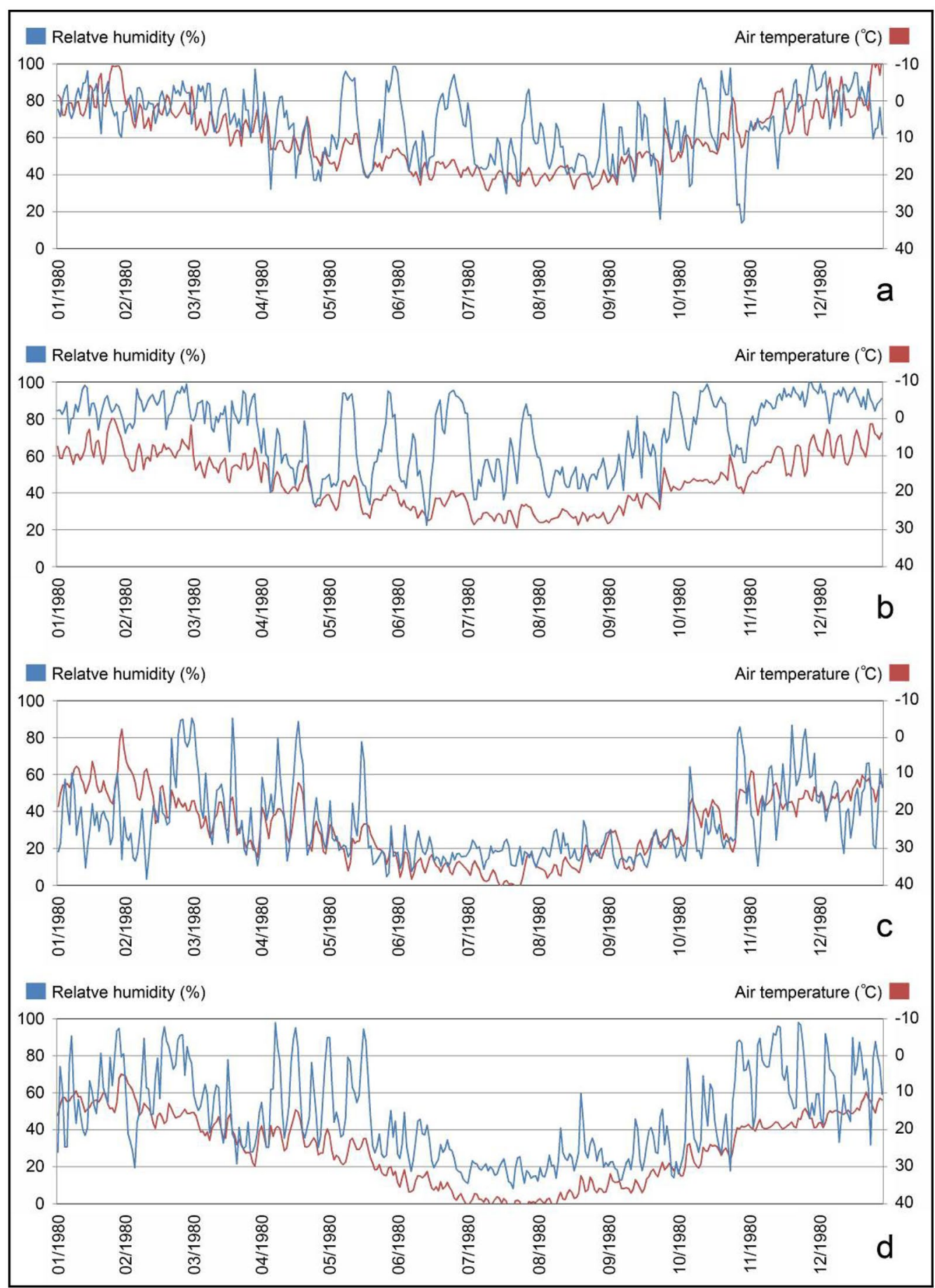

Fig. 3 Adjusted rescaled plot of temperature and relative humidity in daily scale for a Ankara, b Istanbul, c Mashhad, and d Tehran 
height at the level 1000 and $850-\mathrm{hPa}$ (or 1000 and 850$\mathrm{mb}$ ) based on the normal climatology period (1981-2010) via https://www.esrl.noaa.gov/psd/data/composites/ day. Spatial statistics for urban expansion and settlement extension data were collected from global Human Built-up and Settlement Extent (HBASE) hosted by socioeconomic data and applications center of the National Aeronautics and Space Administration (NASA) via https ://sedac.ciesin.columbia.edu/data/set/ulandsat-hbase-v1/ data-download, which is derived from the global land survey of Landsat dataset (Wang et al. 2017; KardaniYazd et al. 2019). Ultimately, the population of urban areas was derived from the 2018 revision of the World Urbanization Prospects via http://esa.un.org/unpd/wup, which has been compiled by the population division of the department of economic and social affairs of the United Nations (WUP 2018).

In detail, the obtained time-series data were obtained in the quality-controlled format from web-based sources. However, all data were controlled based on their coordination, convergence and normality status before statistical analyses to overcome the effects caused by the scale differences of variables (Güler et al. 2002; Thyne et al. 2004). Statistical package for social science (SPSS) software was used to compile, summarize, and analyze the quantitative data by measuring the Pearson correlation test to expose the relationships between dependent index (SWEAT) and independent variables (climatic and anthropogenic).

\section{Results}

\section{Estimation the SWEAT values}

The warmest years between 1880 and 2018 at the global scale are estimated after the year 2000 (Tomczyk and Bednorz 2020), with a maximum in 2016 (mean anomaly of $0.99^{\circ} \mathrm{C}$ ). The year 2018 was classified in the fifth position, with mean anomalies at a level of $0.83{ }^{\circ} \mathrm{C}$ (NOAA 2019). The mentioned the year 2018 in the Middle East regions (principally Turkey and Iran) experienced the more severity due to a remarkable mean anomaly of $1.5-2.5^{\circ} \mathrm{C}$ and $0.9-2.1^{\circ} \mathrm{C}$ at the level 1000 and $850-\mathrm{hPa}$, respectively based on daily air temperature provided by daily NOAA composite anomalous data grids (Fig. 4a, b). These anomalies were also observed in synoptic-scale for geopotential heights at the level 1000 and $850-\mathrm{hPa}$ as an anomalous high-pressure wave with dominant persistency over Iran (Fig. 4c, d). Therefore, investigation of the weather severity indices (e.g., SWEAT index) in a like condition of 2018 could be applied to identify the local and regional evidence of climate change in the urban areas.

Based on the classification of weather severity, the SWEAT daily values were categorized into four classes

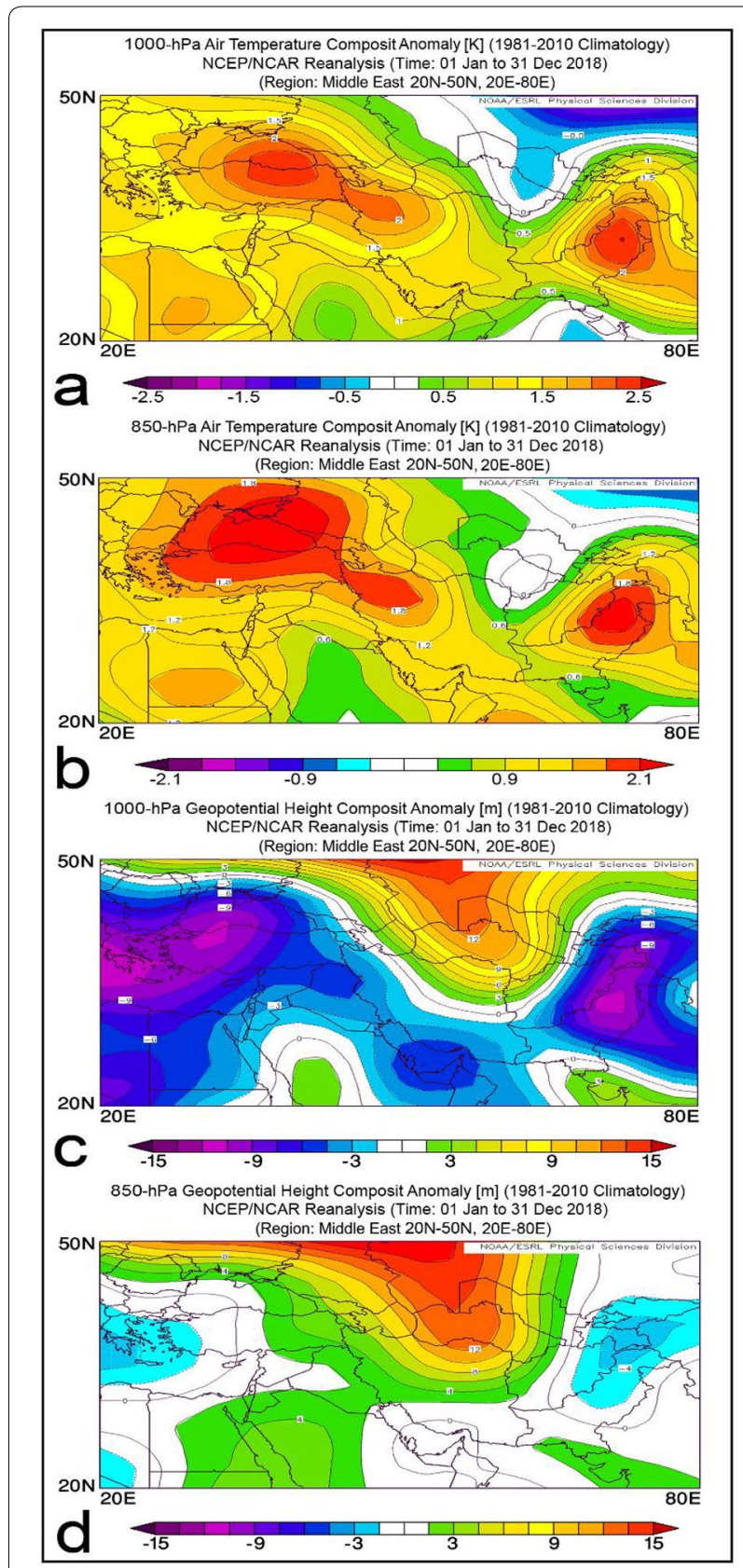

Fig. 4 The composite NCEP/NCAR reanalysis plots of a air temperature anomaly at the level of $1000-\mathrm{hPa}$, $\mathbf{b}$ air temperature anomaly at the level of $850-\mathrm{hPa}$, c geopotential height anomaly at the level of $1000-\mathrm{hPa}$, and $\mathbf{d}$ geopotential height anomaly at the level of $850-\mathrm{hPa}$

of low, high, and extreme categories with SWEAT values of $<200,200-300$, and $>300$, respectively. The thresholds were used the same as those in the original severe weather decision aid, developed by Bauman et al. (2005). In this regard, the SWEAT daily data were classified based on the weather severity in Table 2 . The table revealed 
Table 2 Classification of SWEAT daily data for the study areas based on the weather severity in 2018

\begin{tabular}{|c|c|c|c|c|c|c|c|}
\hline \multirow[t]{2}{*}{ No. } & \multirow[t]{2}{*}{ City } & \multicolumn{2}{|c|}{$<200$} & \multicolumn{2}{|c|}{$200-300$} & \multicolumn{2}{|c|}{$>300$} \\
\hline & & Day & $\%$ & Day & $\%$ & Day & $\%$ \\
\hline 1 & Ankara & 337 & 92.3 & 28 & 7.7 & 0 & 0.0 \\
\hline 2 & Istanbul & 309 & 84.7 & 51 & 14.0 & 5 & 1.4 \\
\hline 3 & Mashhad & 361 & 98.9 & 4 & 1.1 & 0 & 0.0 \\
\hline 4 & Tehran & 349 & 95.6 & 15 & 4.1 & 1 & 0.3 \\
\hline
\end{tabular}

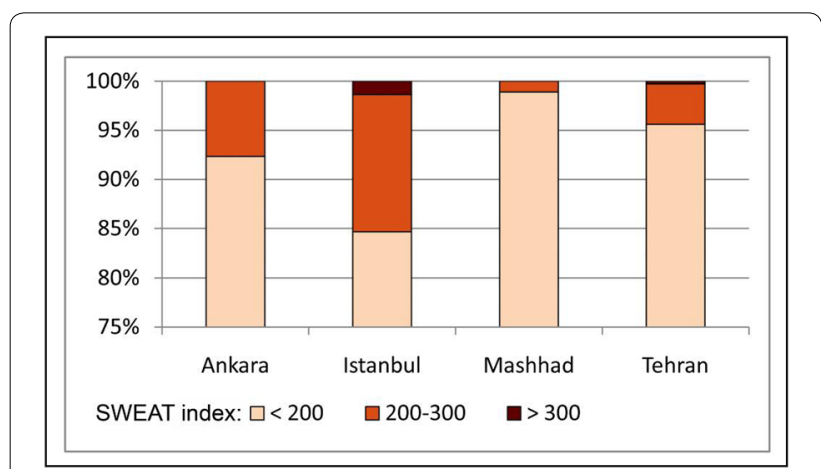

Fig. 5 The percentile contribution the SWEAT daily data to each weather severity class in the study areas (2018)

that only Istanbul city has an extreme weather severity class (SWEAT > 300) at least more than $1 \%$ of the total 365 days in 2018. Overall, the high and extreme severity classes of the weather condition in the Ankara, Istanbul, Mashhad, and Tehran were estimated as 7.7\% (28 days), $15.3 \%$ (56 days), $1.1 \%$ ( 4 days), and $4.4 \%$ (16 days), respectively (Fig. 5). When the value of SWEAT increases the atmospheric stability decreases (Siedlecki 2009). On this basis, Istanbul and Ankara regions have a more unstable and severe weather condition compared with Mashhad and Tehran regions.

In the next step, the mean daily values of the SWEAT index were summarized based on monthly scales for the study areas (Table 3). The data exposed in this table were plotted in two types of diagrams to boost the presentation of the analysis. Fist plot in Fig. 6a depends on the percentile contribution of Monthly scaled mean SWEAT data to each study area and the second plot in Fig. 6b represents the linear variation of data for the study areas. Referring to this Figure, the strongest values of monthly SWEAT among the urban regions are observed for Istanbul and Ankara in March and July months (>150). The comparatively low SWEAT index may reflect the climatic effects of humidity and temperature elements in the index (Wasula et al. 2002).

The weakest data are observed for Mashhad and Tehran in July month $(<60)$. On this basis, the largest values
Table 3 The monthly summarized of the SWEAT values in 2018

\begin{tabular}{lcccc}
\hline Month & Ankara & Istanbul & Mashhad & Tehran \\
\hline Jan & 89 & 132 & 47 & 74 \\
Feb & 107 & 135 & 72 & 112 \\
Mar & 135 & 186 & 83 & 84 \\
Apr & 73 & 75 & 63 & 82 \\
May & 125 & 130 & 72 & 102 \\
Jun & 129 & 137 & 66 & 67 \\
Jul & 158 & 172 & 59 & 37 \\
Aug & 123 & 128 & 72 & 62 \\
Sep & 110 & 130 & 51 & 87 \\
Oct & 105 & 118 & 44 & 115 \\
Nov & 81 & 107 & 60 & 93 \\
Dec & 89 & 92 & 61 & 91 \\
Mean annual & 110 & 129 & 63 & 84 \\
\hline
\end{tabular}

of the monthly SWEAT index in the Ankara and Istanbul relates to the warmest month in the whole of the study areas (Fig. 7a). Nonetheless, the July month is not the driest period in the Ankara and Istanbul regions (Fig. 7b-d). The lowest values of the monthly precipitation, relative humidity, and cloudiness in the study areas depend on August month. Uncooperatively, the highest monthly values are not observed in simultaneous times. For example, the highest values of precipitation in Ankara and Istanbul belong to the May and June months, but in Mashhad and Tehran belongs to October and November months. In general, the monthly severe weather and possible storming conditions in Ankara and Istanbul relate to the warm period of the year. This fact is in accordant with several previous works revealing that the mean SWEAT value has a rise usually during the warm months by around $10 \%$ (Michaelides et al. 2008) and its positive trends may be forced by increases in temperature and humidity capacity in air low-levels (Derubertis 2006). Michaelides et al. (2008) have noted the higher values of the monthly SWEAT index in the warm period as a limitation of the index because the severe weather actually occurs in the low range during the high-temperature periods (Bauman et al. 2005). Nonetheless, the SWEAT index is yet known 


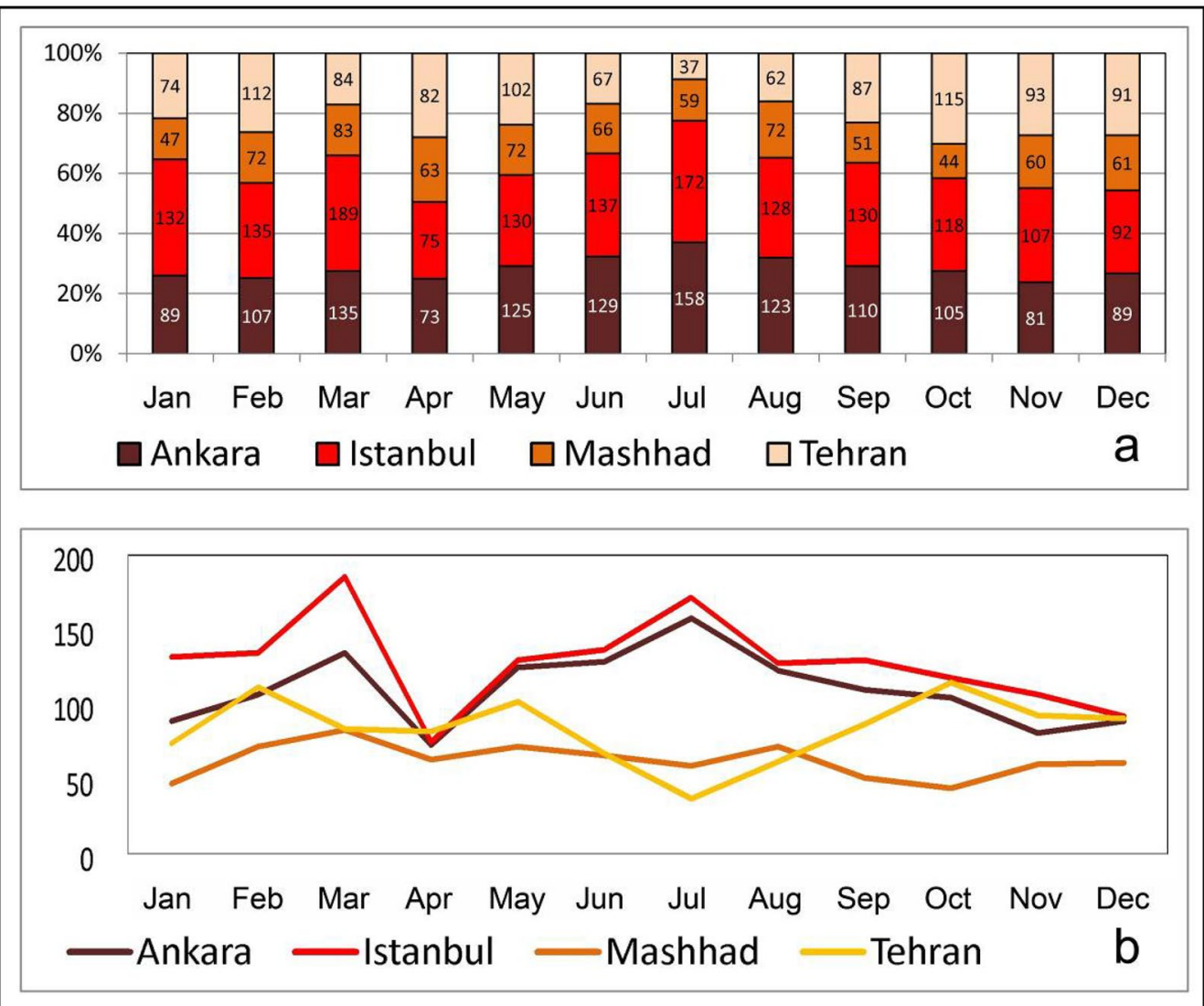

Fig. 6 Monthly scaled mean SWEAT data for $\mathbf{a}$ the percentile contribution of data to each study area and $\mathbf{b}$ linear variation of data for the study areas

as a useful tool for predicting specific weather during the year (Siedlecki 2009). To overcome this limitation, the present study considered the mean annual values in the continuation of the research.

\section{Survey of affecting factors}

In this step, a survey is assumed to recognize independent factors affecting the SWEAT index among several climatic variables (e.g., air temperature, precipitation, relative humidity, and cloudiness) and some urban indicators (e.g., the urban sprawl index and population growth). In this regard, the mean annual values of urban indicators were considered due to the physical nature and static limitation of urban-based indicators. Hence, the mean annual summarizations of the aforementioned independent variables were presented in Tables 4, 5. Based on Table 4, the mean annual values of climatic variables were extracted in addition to values of mean annual SWEAT index. In this regard, the highest values of mean annual SWEAT index (>110 in Ankara and Istanbul) depend on the lowest mean annual temperature values $\left(<17^{\circ} \mathrm{C}\right)$, the highest mean annual precipitation values $(>560 \mathrm{~mm})$, and the highest mean annual relative humidity (>65\%). As well as, the mean annual values of urban independent indicators were estimated in Table 5, including population (million inhabitants), urban expansion $\left(\mathrm{Km}^{2}\right)$, population density (person per $\mathrm{Km}^{2}$ ), and sprawl index (\%). According to the population data in 2018, the largest amount belongs to Istanbul urban region with 14.7 million inhabitants. Considering the urban expansion area of the city, equal $1300 \mathrm{Km}^{2}$, the population density of Istanbul is estimated at 11500 persons per $\mathrm{Km}^{2}$ as the largest population density among the study areas. Based on the urban expansion data, Ankara has the highest expansion area $\left(1400 \mathrm{Km}^{2}\right)$ and accordingly has the lowest population density with value 3500 persons per $\mathrm{Km}^{2}$. Tehran and Mashhad regions have moderate expansion (500-1000 $\left.\mathrm{Km}^{2}\right)$ and moderate density (6000-9000 persons per $\mathrm{Km}^{2}$ ) among the study areas. Ultimately, in this table, an urban sprawl index has been estimated based on the percentile quota of each urban expansion area from the surrounded rectangle zone with area $\sim 3500 \mathrm{Km}^{2}$. On this basis, the highest sprawl index belongs to Ankara (40\%) and the lowest value fits in Mashhad (15\%). The 


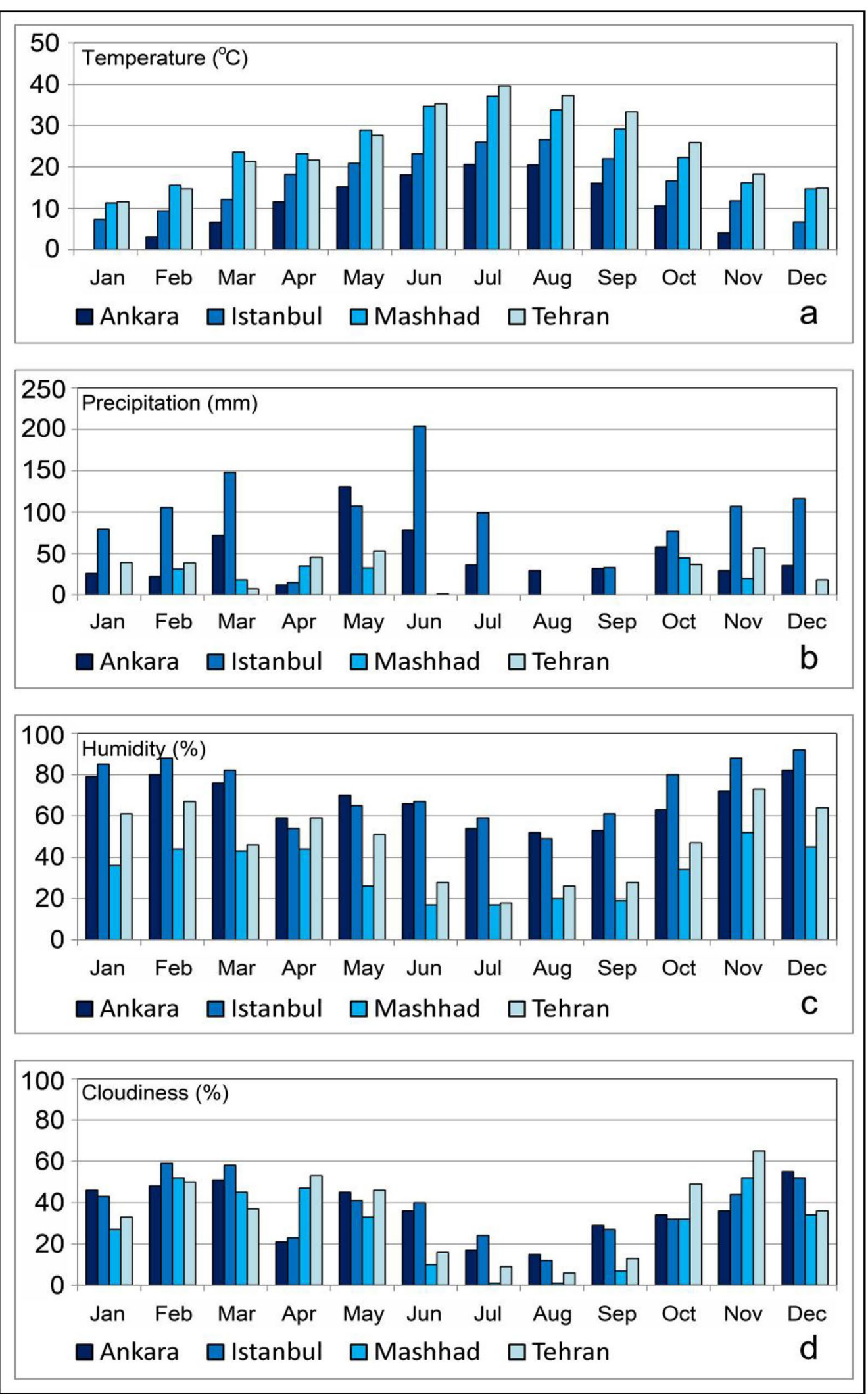

Fig. 7 The percentile contribution of each mean monthly climatic variable to the study areas for a temperature, $\mathbf{b}$ precipitation, c relative humidity, and $\mathbf{d}$ cloudiness 
Table 4 Mean annual values of climatic independent variables in 2018

\begin{tabular}{|c|c|c|c|c|c|c|}
\hline No. & City & Temperature $\left({ }^{\circ} \mathrm{C}\right)$ & Precipitation $(\mathrm{mm})$ & Humidity (\%) & Cloudiness (\%) & $\begin{array}{l}\text { SWEAT } \\
\text { (unit-less) }\end{array}$ \\
\hline 1 & Ankara & 10.3 & 561.2 & 67 & 36 & 110 \\
\hline 2 & Istanbul & 16.8 & 1091.9 & 73 & 38 & 129 \\
\hline 3 & Mashhad & 24.2 & 181.5 & 33 & 28 & 63 \\
\hline 4 & Tehran & 25.1 & 293.5 & 47 & 34 & 84 \\
\hline
\end{tabular}

moderate values (30-35\%) depend on the Istanbul and Tehran urban regions.

The comparison of these urban-based indicators with the SWEAT index revealed that the highest values of mean annual SWEAT index (>110) in Ankara and Istanbul can correspond to the largest values of the urban expansion area (1300-1400 $\left.\mathrm{Km}^{2}\right)$ and urban sprawl index (35-40\%). Hence, the factors influencing the severe weather index (SWEAT) in the study urban regions can include both climatic substantial elements (e.g., temperature and precipitation) and urban development indicators (e.g., urban expansion and sprawl). In the final step, a correlation test was calculated to present robust statistical evidence instead of a descriptive context, identifying the factors affecting the SWEAT index in the urban areas.

The correlations between the annual SWEAT index and several independent factors were shown in Table 6, based on the summarized annual data in four urban areas. The results of this Table confirmed the very strong and positive correlations ( $\mathrm{R}$ from 0.94 to 0.99 ) between the SWEAT index and independent climatic variables of precipitation, relative humidity, and cloudiness at $95 \%$ of the confidence level based on annual data. As well, the relatively strong and positive correlations ( $\mathrm{R}$ from 0.86 to 0.91) between the SWEAT index and independent urban indicators of urban expansion and sprawl index were observed at $85-90 \%$ of the confidence level. In vice versa, a negative and intermediate relationship was estimated between SWEAT and air temperature ( $\mathrm{R}$ equal -0.73 ). Hence, the results of the correlation test confirm the

Table 5 Mean annual values of urban independent indicators in 2018

\begin{tabular}{llcccc}
\hline No. City & $\begin{array}{l}\text { Population } \\
\text { (million) }\end{array}$ & $\begin{array}{l}\text { Urban } \\
\text { expansion } \\
\left.\mathbf{( K m}^{2}\right)\end{array}$ & $\begin{array}{l}\text { Population } \\
\text { density } \\
\text { (person } \\
\text { per Km } \mathbf{~ K m}^{\mathbf{}}\end{array}$ & $\begin{array}{l}\text { Sprawl } \\
\text { index } \\
\mathbf{( \% )}\end{array}$ \\
\hline 1 & Ankara & 4.9 & 1400 & 3500 & 40 \\
2 & Istanbul & 14.7 & 1300 & 11,500 & 35 \\
3 & Mashhad & 3.0 & 500 & 6000 & 15 \\
4 & Tehran & 8.9 & 1000 & 9000 & 30 \\
\hline
\end{tabular}

effective role of climatic elements (positive or negative) and urban expansion indicators (positive) in increasing annual severe weather index of annual SWEAT in the urban areas.

Based on the finding, there is no strong relationship between the SWEAT index and population number or population density ( $\mathrm{R}$ from 0.34 to 0.73 ). This fact can explain that the concentrated population in a region has a less relation with local variability of climate, while the expansion of urban structures and settlements is more direct correlative with climatic elements (e.g., weather severity and air perturbation potential). Furthermore, this evidence approves an obscure link between enhancing sprawl expansion and low-density development (Rabbani et al. 2017). However, the physical elements of urban geography such as latitude and longitude characteristics revealed a positive strong correlation ( $R$ equal 0.92 ) and a negative strong correlation (R equal -0.99 ) with SWEAT index, respectively at $90-99 \%$ of the confidence level. The relationship between the SWEAT index and the altitude element was estimated as a negative and intermediate ( $R$ equal -0.78).

\section{Discussion}

The severe weather threat index (SWEAT) is a significant weather predictor, which can reflect the air perturbation and severe weather in the air levels of the urban atmosphere. In the present study, the SWEAT index in the four urban areas of Turkey and Iran, including Istanbul, Ankara, Tehran, and Mashhad, was considered to identify its affecting factors such as climatic variables (air temperature, precipitation, relative humidity, and cloudiness) and urban indicators (urban expansion and population growth). For this purpose, the upper air daily sounding data were obtained from the University of Wyoming database for 365 days in 2018.

Based on the mean annual data, the enhancement of SWEAT values in the four case studies can be affected by the increase of urban expansion and sprawl in addition to the increase of cloudiness, humidity, and precipitation rates. Hence, the climatic variables of precipitation, humidity, and cloudiness can be considered as the mediator variables in this study, enhancing the relationships 


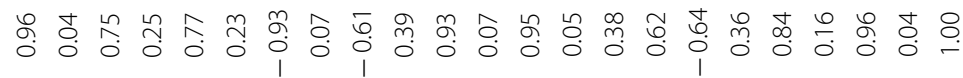

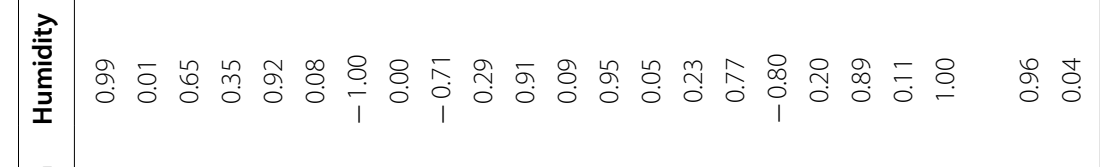

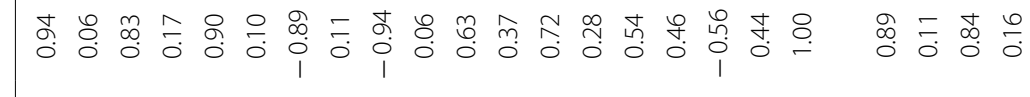

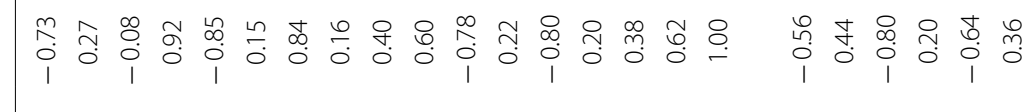

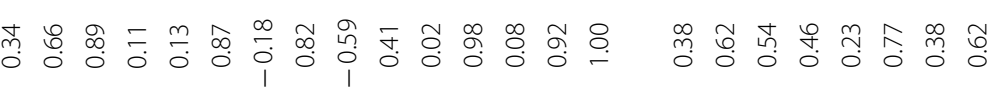

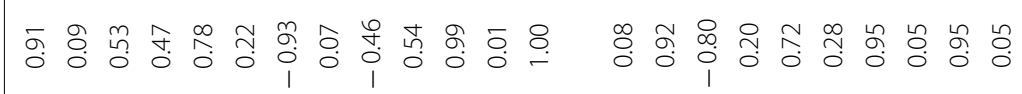

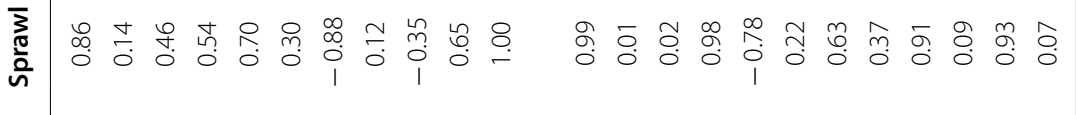

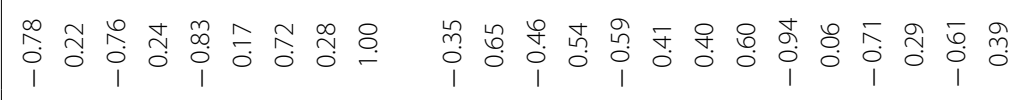

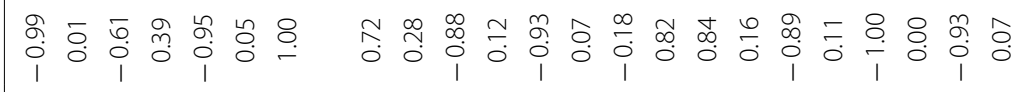

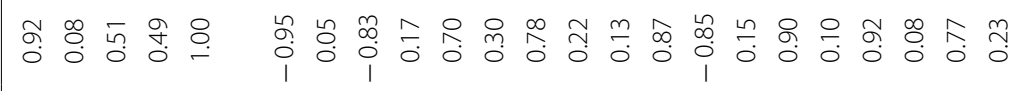

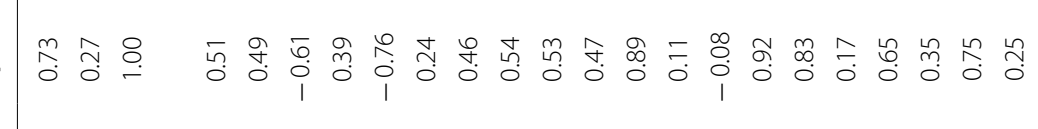

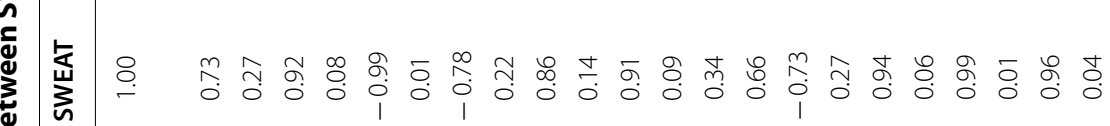

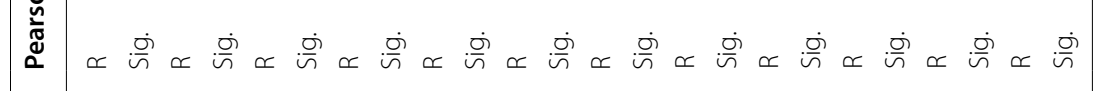

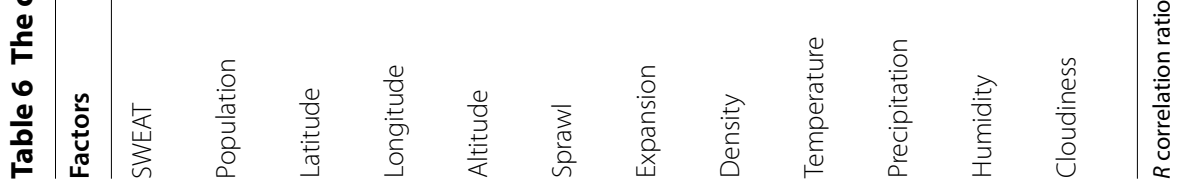




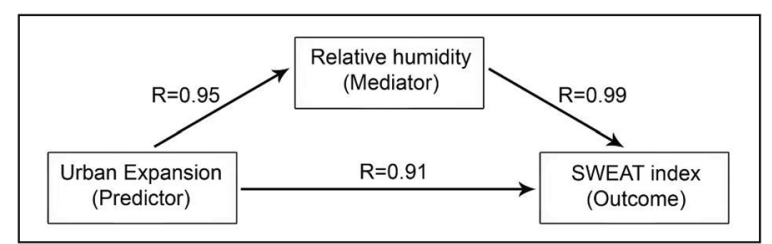

Fig. 8 Mediated relationship model among the study variables (urban expansion $=$ predictor, relative humidity $=$ mediator, and SWEAT index $=$ outcome)

between the urban expansion indicators and the annual SWEAT index. The mediator variable (e.g., humidity) usually affects the association between an independent variable (e.g., urban expansion) and an outcome variable (e.g., SWEAT), providing information about how or why both mentioned variables and outcomes are vigorously associated (Bennett 2000; Ro 2012). A mediator is a mechanism through which a predictor influences an outcome variable (Baron and Kenny 1986; Frazier et al. 2004). An example of a mediated relationship model among the study variables is shown in Fig. 8. In this regard, increase in urban expansion reflects an increase in demand for physical construction, transportation, and assumption of fuels (Mansouri Daneshvar et al. 2019b), inducing the heat capacity, humidity, and dewpoint, as a direct measure of low-level moisture and humidity content (Peppier 1988). According to research, the increase of dewpoint certainly increases the SWEAT index (Derubertis 2006). Hence, a mediated model among the urban expansion, humidity, and SWEAT variables can be presented as a basis for further researches.

Furthermore, the severe weather also could be weakened by the increase in air temperature and geographical altitude (elevation heights). In this manner, the climatic variable of air temperature can be considered as a moderator variable in this study, modifying the relationships between the urban expansion indicators and the annual SWEAT index. Unlike a mediator, the moderator is a variable that influences the strength or the direction of a relationship between a predictor variable and an outcome variable (Rose et al. 2004). Despite the researches on SWEAT index in the previous works to reveal the statistical modeling of the severe weather (e.g., Sioutas and Flocas 2003; Derubertis 2006; Tyrrell 2007; Kunz 2007; Michaelides et al. 2008; Siedlecki 2009; Rhodes and Senkbeil 2014; Baltaci et al. 2018; Abshaev et al. 2019), the present study tried to investigate the possible relations with affecting criteria. However, we need new researches with more spatial cases and temporal windows to understand the mediation and modification role of independent factors (e.g., humidity, temperature, and elevation) on the severe weather perturbation in the urban regions.
Ultimately, analytic limitations of the SWEAT index can be categorized into three classes: (1) limitation of daily-scale big-data compilation from radiosonde stations, (2) estimation of the higher values of mean monthly SWEAT index in the warm months, and (3) comparison with the physical nature and static limitation of artifact indicators. To overcome these limitations, the statistical analysis can consider the mean annual values through compilation, estimation, and comparison of data.

\section{Conclusion}

Based on the SWEAT daily values, the high and extreme severity classes of the weather condition in the Ankara, Istanbul, Mashhad, and Tehran were estimated as 7.7\% (28 days), $15.3 \%$ (56 days), $1.1 \%$ (4 days), and $4.4 \%$ (16 days), respectively. The strongest values of monthly SWEAT among the urban regions are observed for Istanbul and Ankara in March and July months (>150). Also, the highest values of mean annual SWEAT index $(>110)$ in Ankara and Istanbul were matched to the largest values of urban expansion area $\left(1300-1400 \mathrm{Km}^{2}\right)$ and urban sprawl index (35-40\%), where have the highest mean annual precipitation values $(>560 \mathrm{~mm})$, and relative humidity $(>65 \%)$ among the study areas.

The statistical correlation tests in the annual scale confirmed the effective role of aforementioned climatic elements of precipitation, relative humidity, and cloudiness ( $\mathrm{R}$ from 0.94 to 0.99 ) and the urban expansion indicators ( $\mathrm{R}$ from 0.86 to 0.91 ) in increasing annual severe weather index of SWEAT at above 85-95\% of confidence level. Ultimately, this research assumed the climatic variables $\mathrm{f}$ precipitation, humidity, and cloudiness as the mediator variables, enhancing the link between urban expansion indicators and outcome SWEAT index. Thus, the research described the variable of air temperature and elevation height as the moderator variables.

The main implication of this research can be applied in future academic researches to further study the mediated or the moderated role of variables affecting severe weather in the urban regions. In this regard, the study of the mediated models among the urban expansion, humidity, and SWEAT variables is suggested. Besides, the research with more spatial cases and temporal windows is recommended to understand the modification role of growing air temperature and elevation height on the severe weather perturbation in urban regions.

\section{Abbreviations}

APDRC: Asia pacific data research center; DEM: Digital elevation model; HBASE: Human built-up and settlement extent; NASA: National aeronautics and space administration; NCEP: National centers for environmental prediction; NOAA: National oceanic and atmospheric administration; SWEAT: Severe weather threat index; WUP: World urbanization prospects. 


\section{Acknowledgements}

We thank two anonymous reviewers for technical suggestions on data interpretations.

\section{Authors' contributions}

All authors were equally involved in analyzing and editing the paper. All authors read and approved the final manuscript.

\section{Funding}

This study was not funded by any grant.

\section{Availability of data and materials}

The data that support the findings of this study are available from the corresponding author upon request.

\section{Ethics approval and consent to participate}

This article does not contain any studies with participants performed by any of the authors.

\section{Consent for publication}

Not applicable.

\section{Competing interests}

The authors declare that they have no Competing interests.

\section{Informed consent}

Informed consent was obtained from individual participant included in the study.

\section{Author details}

${ }^{1}$ College of Geography and Urban Planning, Research Institute of Shakhes Pajouh, Isfahan, Iran. ${ }^{2}$ Department of Urban Planning and Design, Mashhad Branch, Islamic Azad University, Mashhad, Iran. ${ }^{3}$ Department of Geography and Natural Hazards, Research Institute of Shakhes Pajouh, Isfahan, Iran.

\section{Received: 6 March 2020 Accepted: 20 May 2020}

Published online: 25 May 2020

\section{References}

Abshaev MT, Abshaev AM, Mikhailovskiy YP, Sinkevich AA, Popov VB, Adzhiev AK (2019) Characteristics of the supercell Cb thunderstorm and electrical discharges on 19 August 2015, North Caucasus: a case study. Preprints Version. https://doi.org/10.20944/preprints201912.0033.v1

Alpert P, Kishcha P, Kaufman YJ, Schwarzbard R (2005) Global dimming or local dimming?: effect of urbanization on sunlight availability. Geophys Res Lett 32(L17):802

Baltaci H, Akkoyunlu BO, Tayanc M (2018) An extreme hailstorm on 27 July 2017 in Istanbul, Turkey: synoptic scale circulation and thermodynamic evaluation. Pure Appl Geophys 175:3727-3740

Baron RM, Kenny DA (1986) The moderator mediator variable distinction in social psychological research: conceptual, strategic, and statistical considerations. J Pers Soc Psychol 51:1173-1182

Bauman WH, Wheeler MM, Short DA (2005). Severe weather forecast decision aid. NASA Technical Reports Server. NASA/CR-2005-212563, Rept-05-001

Bazrkar MH, Zamani N, Eslamian S, Eslamian A, Dehghan D (2015) Urbanization and climate change. In: Filho WL (ed) Handbook of climate change adaptation. Springer Verlag, Berlin, pp 619-655

Beck HE, Zimmermann NE, McVicar TR, Vergopolan N, Berg A, Wood EF (2018) Present and future 374 Köppen-Geiger climate classification maps at 1-km resolution. Scientific Data 5:180214

Bennett JA (2000) Mediator and moderator variables in nursing research: conceptual and statistical differences. Res Nurs Health 23:415-420

Bidner A (1970). The Air Force Global Weather Central severe weather threat (SWEAT) index-a preliminary report. Air Weather Service Sciences Review, AWS RP015-2 No. 70-3: 2-5

Das S (2017) Severe thunderstorm observation and modeling - a review. Vayu Mandal 43(2):1-29

Derubertis D (2006) Recent trends in four common stability indices derived from U.S. radiosonde observations. J Clim 19:309-323
Dodman D (2009) Blaming cities for climate change? An analysis of urban greenhouse gas emissions inventories. Environ Urbanization 21:185-201

Dulal HB, Brodnig G, Onoriose CG (2011) Climate change mitigation in thetransport sector through urban planning: a review. Habitat Int 35:494-500

Elasha BO (2010). Mapping of climate change threats and human development impacts in the Arab region. United Nations Development Programme, Arab Human Development Report (AHDR), Research Paper Series, pp 51

Fan H, Sailor DJ (2005) Modeling the impacts of anthropogenic heating on the urban climate of Philadelphia: a comparison of implementations in two PBL schemes. Atmos Environ 39.73-84

Fanni Z, Hosayni Z, Afsharmanesh H, Nazemmahalleh MA, Rastegar A (2013) The effects of urban environment on climate changes, case study: Tehran, Iran. J Tethys 1(2):138-147

Frazier PA, Tix AP, Barron KE (2004) Testing moderator and mediator effects in counseling psychology. J Counsel Psychol 51:115-134

Galway JG (1956) The lifted index as a predictor of latent instability. Bull Am Meteor Soc 37:528-529

Gohari A, Eslamian S, Abedi-Koupaei J, Massah-Bavani A, Wang D, Madani K (2013) Climate change impacts on crop production in Iran's ZayandehRud River Basin. Sci Total Environ 442:405-419

Güler C, Thyne GD, McCray JE, Turner AK (2002) Evaluation of graphical and multivariate statistical methods for classification of water chemistry data. Hydrogeol J 10:455-474

Hijmans RJ, Cameron SE, Parra JL, Jones PG, Jarvis A (2005) Very high resolution interpolated climate surfaces for global land areas. Int J Climatol 25(15):1965-1978

Kaltenböck R, Diendorfer G, Dotzek N (2009) Evaluation of thunderstorm indices from ECMWF analyses, lightning data and severe storm reports. Atmos Res 93:381-396

Kardani-Yazd N, Kardani-Yazd N, Mansouri Daneshvar MR (2019) Strategic spatial analysis of urban greenbelt plans in Mashhad city, Iran. Environ Syst Res 8:30

Kunz M (2007) The skill of convective parameters and indices to predict isolated and severe thunderstorms. Nat Hazards Earth Syst Sci 7:327-342

Makar PA, Gravel S, Chirkov V, Strawbridge KB, Froude F, Arnold J, Brook J (2006) Heat flux, urban properties, and regional weather. Atmos Environ 40:2750-2766

Mansouri Daneshvar MR, Ebrahimi M, Nejadsoleymani H (2019a) An overview of climate change in Iran: facts and statistics. Environ Syst Res 8:7

Mansouri Daneshvar MR, Rabbani G, Shirvani S (2019b) Assessment of urban sprawl effects on regional climate change using a hybrid model of factor analysis and analytical network process in the Mashhad city, Iran. Environ Syst Res 8:23

Michaelides SC, Savvidou K, Nicolaides KA, Orphanou A, Photiou G, Kannaouros C (2008) Synoptic, thermodynamic and agroeconomic aspects of severe hail events in Cyprus. Nat Hazards Earth Syst Sci 8:461-471

Miller RC (1972). Notes on the analysis of severe storm forecasting procedures of the air force global weather center AFGWC Tech. Rep. 200 (rev.). Air Weather Service, Scott AFB, IL

Miller PW, Mote TL (2018) Characterizing severe weather potential in synoptically weakly forced thunderstorm environments. Nat Hazards Earth Syst Sci 18:1261-1277

NOAA (2019). Global Climate Report-Annual 2019 archived by National Oceanic and Atmospheric Administration. https://www.ncdc.noaa.gov/ sotc/global/201913. Accessed 2019

Peel MC, Finlayson BL, McMahon TA (2007) Updated world map of the Köppen-Geiger climate 376 classification. Hydrol Earth Syst Sci 11:1633-1644

Peppier R (1988). A review of static stability indices and related thermodynamic parameters. Illinois state water survey climate and meteorology section 104, $87 \mathrm{pp}$

Rabbani G, Shafaqi S, Rahnama MR (2017) Urban sprawl modeling using statistical approach in Mashhad, northeastern Iran. Model Earth Syst Environ 4:141-149

Rhodes CL, Senkbeil JC (2014) Factors contributing to tornadogenesis in landfalling Gulf of Mexico tropical cyclones. Meteorol Appl 21:940-947

Ro H (2012) Moderator and mediator effects in hospitality research. Int J Hospitality Manage 31:952-961 
Rose BM, Holmbeck GN, Coakley RM, Franks EA (2004) Mediator and moderator effects in developmental and behavioral pediatric research. J Dev Behav Pediatr 25:58-67

Sarvari H (2019) A survey of relationship between urbanization and climate change for major cities in Iran. Arab J Geosci 12:131

Shepherd G, Terradellas E, Baklanov A, Kang U, Sprigg W, Nickovic S, Boloorani AD, Al-Dousari A, Basart S, Benedetti A et al (2016) Global assessment of sand and dust storms. UNEP, WMO, UNCCD; United Nations Environment Programme, Kenya, p 123

Showalter AK (1953) A stability index for thunderstorm forecasting. Bull Am Meteor Soc 34:250-252

Siedlecki M (2009) Selected instability indices in Europe. Theoret Appl Climatol 96:85-94

Sioutas MV, Flocas HA (2003) Hailstorms in Northern Greece: synoptic patterns and thermodynamic environment. Theoret Appl Climatol 75:189-202

Thyne G, Güler C, Poeter E (2004) Sequential analysis of hydrochemical data for watershed characterization. Ground Water 42:711-772

Tomczyk AM, Bednorz E (2020) The extreme year-analysis of thermal conditions in Poland in 2018. Theoret Appl Climatol 139:251-260

Tyrrell J (2007) Winter tornadoes in Ireland: the case of the Athlone tornado of 12 January 2004. Atmos Res 83:242-253
Wang J, Sheng Z, Zhou B, Zhou S (2014) Lightning potential forecast over Nanjing with denoised sounding-derived indices based on SSA and CS-B Pneural network. Atmos Res 137:245-256

Wang P, Huang C, de Colstoun ECB, Tilton JC, Tan B (2017). Documentation for the global human built-up and settlement extent (HBASE) dataset from Landsat. Palisades, NY: NASA Socioeconomic Data and Applications Center. https://doi.org/10.7927/H48W3BCM. Accessed 2019.

Wasula AC, Bosart LF, Lapenta KD (2002) The Influence of Terrain on the severe weather distribution across interior eastern New York and Western New England. Water Forecast 17:1277-1289

WUP (2018). World urbanization prospects. Population division of the department of economic and social affairs of the United Nations. https://popul ation.un.org/wup. Accessed 2019

\section{Publisher's Note}

Springer Nature remains neutral with regard to jurisdictional claims in published maps and institutional affiliations.

\section{Submit your manuscript to a SpringerOpen ${ }^{\circ}$ journal and benefit from:}

- Convenient online submission

- Rigorous peer review

- Open access: articles freely available online

- High visibility within the field

- Retaining the copyright to your article

Submit your next manuscript at $\boldsymbol{\nabla}$ springeropen.com 